\title{
Responsabilidade Social Corporativa: uma revisão
}

\author{
Autoria \\ Vanessa Custódio Zorzetti Pollon - vanessacustodiozorzetti@ hotmail.com \\ Prog de Pós-Grad em Admin de Empresas - PPGA /Mackenzie - Universidade Presbiteriana Mackenzie \\ Maria Luisa Mendes Teixeira - marialuisa.teixeira@mackenzie.br \\ Prog de Pós-Grad em Admin de Empresas - PPGA /Mackenzie - Universidade Presbiteriana Mackenzie \\ Patrícia Teixeira Maggi Silva - patriciatmaggi@gmail.com \\ Prog de Pós-Grad em Admin de Empresas - PPGA /Mackenzie - Universidade Presbiteriana Mackenzie
}

\section{Resumo}

O conceito de Responsabilidade Social Corporativa (RSC), apesar de amplamente estudado há várias décadas, ainda não apresenta convergência conceitual. A crescente cobrança da sociedade para que as empresas aperfeiçoem sua relação de troca entre o que obtêm da sociedade e o que devolvem a ela, talvez justifique o aumento do interesse acadêmico pelos estudos sobre RSC, especialmente após os anos 2000.

Este estudo teve como objetivo revisar a produção científica sobre a RSC, com o propósito de contribuir para o avanço do conhecimento sobre a responsabilidade social das Organizações. Estudo teórico que percorreu os marcos históricos do séc. XX ao séc. XXI, as abordagens teóricas mais utilizadas nos estudos sobre o tema, as dimensões éticas da RSC, o estudo bibliométrico dos 37 conceitos de RSC abordados por Dahlsrud (2008), e a análise de conteúdo desses conceitos, explorando as dimensões éticas deontológicas e teleológicas dos conceitos, de modo a contribuir para o avanço do conhecimento sobre a responsabilidade social das Organizações.

Os estudos sobre responsabilidade social corporativa evidenciam a dimensão ética deontológica para a maioria dos conceitos sobre RSC, a análise dos conceitos e de suas dimensões éticas no tempo apresenta potencial para que venham a legitimar uma mudança de tendência. 


\section{Introdução}

A Responsabilidade Social Corporativa (RSC) envolve a busca das organizações por uma relação de troca entre elas, o que obtêm da sociedade e o que devolvem a ela. O mundo dos negócios enfrenta uma crescente pressão para adotar ou melhorar sua responsabilidade social corporativa (BOULOUTA; PITELIS, 2014). E a crescente cobrança da sociedade para que as empresas aperfeiçoem essa relação de troca talvez justifique o aumento do interesse acadêmico pelos estudos sobre RSC, especialmente após os anos 2000.

Tomando como base os artigos sobre responsabilidade social corporativa, verifica-se que, embora seja um tema amplamente estudado, os pesquisadores ainda não convergem em torno de um conceito (SAEIDI et al., 2015). Carroll (2015) destaca estudos que apresentam 37 definições diferentes para RSC, e indica que, nas comunidades empresariais ou acadêmicas, cada um desses conceitos ganhou destaque, de tal forma que eles são hoje onipresentes, seja como palavra-chave ou discurso. Apesar da falta de consistência conceitual, Carroll (2015) menciona a relevância da RSC quando suas políticas são cuidadosamente implementadas, pois podem ajudar as empresas a fechar novos negócios; aumentar a retenção de clientes; melhorar o relacionamento entre clientes e fornecedores; atrair, motivar e manter a força de trabalho satisfeita; reduzir custos operacionais e de energia; gerenciar riscos; gerar diferenciais competitivos; oferecer acesso e oportunidades de financiamento; e gerar um posicionamento positivo de publicidade e oportunidades de mídia.

No entanto, a falta de convergência em torno de um conceito único de RSC pode levar as empresas a considerar que realizam práticas de $\mathrm{RSC}$, e diferir de forma relevante quanto à RSC que praticam, chegando a resultados diversos.

Diante do exposto, o objetivo deste estudo é revisar a produção científica sobre a RSC, descrevendo seus marcos históricos do séc. XX ao séc. XXI, as abordagens teóricas mais utilizadas nos estudos sobre o tema, as dimensões éticas da RSC, o estudo bibliométrico dos 37 conceitos de RSC abordados por Dahlsrud (2008), e a análise de conteúdo desses conceitos, explorando as dimensões éticas deontológicas e teleológicas dos conceitos, de modo a contribuir para o avanço do conhecimento sobre a responsabilidade social das Organizações.

\subsection{Responsabilidade Social Corporativa (RSC) do século XX ao século XXI}

O crescimento do interesse pelos estudos pode ser verificado pelo número de obras indexadas pela EBSCO com Responsabilidade Social Corporativa ou RSC no título. Dos anos 1960 aos anos 1990 foram indexados nessa plataforma 228 estudos; dos anos 2000 a 2010 esse número cresceu para 2.267, e de 2010 a 2017 houve um aumento ainda mais expressivo, de 4.185 obras, o que corresponde a $63 \%$ do total de estudos, indexadas em apenas oito anos. Frynas e Yamahaki (2016) acreditam que o aumento do interesse por estudos sobre RSC está mais relacionado ao crescimento das produções acadêmicas do que, necessariamente, ao desenvolvimento teórico da RSC. As raízes da RSC podem ser encontradas na década de 1930, na troca de artigos entre Berle e Dodd sobre o papel de gerentes (OKOYE, 2009). Porém, Carroll (2015) relata que somente a partir de 1950 o poder dos negócios aumentou e, em consequência, cresceram também as ideias sobre responsabilidade social. Bowen (1953) escreveu sobre a responsabilidade social do empresário, considerando suas obrigações perante a sociedade em geral.

A década de 1960 teve seu início marcado pelo lirismo oriundo dos anos de 1950 e uma segunda metade marcada pelo início da explosão do consumo e um espírito de luta do povo, em que o "sonho americano" começava a não empolgar os jovens. Ela pode ser considerada o início do moderno movimento de RSC. Naquela época, as empresas se dedicavam a questões relacionadas à filantropia, o que ficou conhecido como "clube dos cinco por cento", pois doavam esse percentual de seus lucros, sem impostos, para a caridade (CARROLL, 2015). A mobilização social, os direitos civis, os direitos das mulheres e do consumidor foram os precursores dos movimentos relacionados à responsabilidade social 
corporativa; a partir daí, as décadas subsequentes consolidaram as manifestações das expectativas da sociedade em todo o mundo.

A década de 1970, marcada por combates e guerras em que eclodiram a violência política e a luta armada, também assistiu ao aumento das revoluções comportamentais, com legislação e regulamentos sociais para normatizar questões relacionadas aos movimentos sociais; com isso, ações referentes ao tema RSC puderam ser mais bem gerenciadas (CARROLL, 2015). Ainda nessa década, Carroll (1979) incorpora ao conceito de RSC as dimensões econômicas, legais, éticas e discricionárias do desempenho do negócio.

A década de 1980 foi marcada por acontecimentos políticos e sociais, além da migração da era industrial para o início da era da informação. Em 1980, o presidente americano Ronald Reagan pediu que as empresas enfrentassem com efetividade os problemas sociais, e, a partir de 1990, a globalização enfatizou a competitividade das empresas, acentuando os méritos e deméritos relacionados à reputação, devido à visibilidade mundial. Além disso, a preocupação das empresas com sua imagem internacional foi um grande incentivo para que planejassem com maior cuidado suas responsabilidades para com as comunidades em que atuavam. Nessa década, os investidores ganharam visibilidade, pois passaram a questionar o fato de as empresas estarem preocupadas com as minorias, ao invés de atenderem às suas expectativas, pois também eram partes interessadas no negócio (CARROLL, 2015).

Outra importante contribuição para os estudos de RSC foi a de Wood (1991), que revisou e ampliou o modelo de Wartick e Cochran (1985), que aborda (a) princípios motivadores, (b) processos comportamentais, e (c) resultados observáveis de ações corporativas, relacionando-os com o desempenho social corporativo (DSC), de modo que seja possível analisar princípios, processos e resultados.

O século XXI iniciou com uma década marcada por escândalos éticos. A economia mundial sofreu uma intensa crise em 2008, que trouxe à tona acusações de acordos éticos questionáveis.

Friedman (2009) defende que a responsabilidade social da empresa é a busca pelo lucro, e que RSC, entendida como ajuda às atividades de caridade, somente poderia ser aceita caso os impostos fossem abolidos da sociedade, uma vez que a responsabilidade social das empresas já é praticada quando elas pagam seus impostos.

A Figura 1 sintetiza os principais marcos históricos da RSC, mostrando um percurso que iniciou com atividades relacionadas à filantropia, em que a sociedade demandava das organizações que seus interesses estivessem na pauta dos interesses organizacionais, passando a percorrer o caminho de atendimento de padrões e legislações sociais, e deslocando-se na atualidade para crises econômicas e éticas, apesar de a sociedade continuar demandando às organizações que preocupações com as questões sociais permaneçam na pauta organizacional.

Figura 1. Principais marcos históricos da RSC

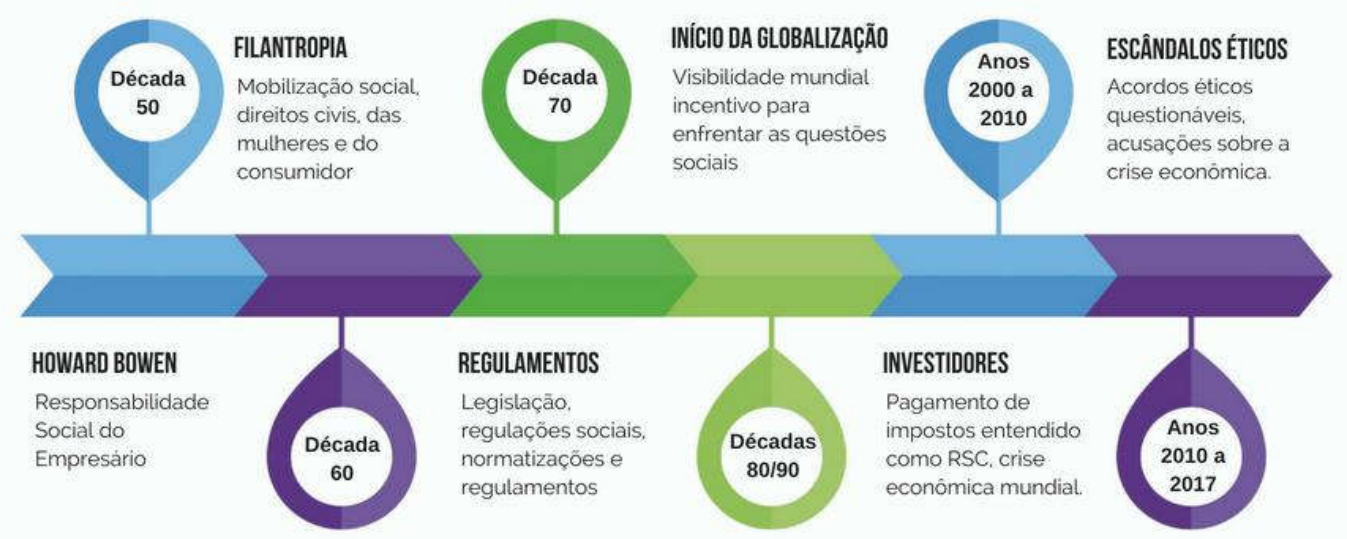

Fonte: Elaborado pelas autoras (2018) 


\subsection{Abordagens teóricas e dimensões éticas da RSC}

Duque Orozco, Cardona Acevedo e Rendón Acevedo (2013) salientam que, apesar de o conceito de RSC ter sido amplamente estudado, sua inconsistência conceitual permanece. Neste sentido, o presente estudo está baseado na análise das abordagens teóricas que orientam a RSC e as dimensões éticas dos conceitos de RSC.

\subsubsection{Abordagens teóricas da RSC}

A inconsistência conceitual da RSC pode estar relacionada à quantidade de perspectivas sobre as quais o fenômeno tem sido estudado. Frynas e Yamahaki (2016), em estudo contendo revisão e roteiro de abordagens teóricas, analisaram o conteúdo de 462 artigos acadêmicos, referente ao período de 1990 a 2014. O Quadro 1 mostra quais as abordagens mais amplamente adotadas na literatura de RSC.

\begin{tabular}{|c|c|c|c|c|c|c|}
\hline Perspectivas aplicadas & $\begin{array}{c}1990- \\
1994\end{array}$ & $\begin{array}{c}1995- \\
1999\end{array}$ & $\begin{array}{l}2000- \\
2004\end{array}$ & $\begin{array}{l}2005- \\
2009\end{array}$ & $\begin{array}{c}2010- \\
2014\end{array}$ & $\begin{array}{l}\text { Total } \\
\text { de } 25 \\
\text { anos }\end{array}$ \\
\hline Partes interessadas & 6 & 12 & 21 & 55 & 112 & 206 \\
\hline Institucional & 1 & 5 & 8 & 47 & 80 & 141 \\
\hline Legitimidade & 1 & 6 & 10 & 24 & 32 & 73 \\
\hline Teoria da agência & 2 & 1 & 7 & 8 & 24 & 42 \\
\hline Visão baseada em recursos & 0 & 5 & 6 & 9 & 21 & 41 \\
\hline Teoria da dependência de recursos & 0 & 1 & 2 & 8 & 13 & 24 \\
\hline De outros & 1 & 0 & 8 & 21 & 54 & 84 \\
\hline
\end{tabular}

Fonte: Baseado em Frynas e Yamahaki (2016)

Os resultados encontrados por Frynas e Yamahaki (2016) demonstram que os estudos são majoritariamente orientados pelas perspectivas partes interessadas e institucional; por essa razão, essas duas abordagens são descritas a seguir.

A abordagem das partes interessadas (stakeholders) presume as ações corporativas como resultado direto de pressões de diferentes partes interessadas, relacionadas à dependência do poder (FREEMAN; REED 1983; JAWAHAR; MCLAUGHLIN, 2001; CLARKSON 1995) ou reivindicação de legitimidade (HILL; JONES, 1992, LANGTRY, 1994). Freeman (1984) definiu partes interessadas (stakeholders) como qualquer grupo ou indivíduo que pode afetar ou é afetado pela realização dos objetivos da empresa. McWilliams, Siegel e Wright (2006) explicam que a abordagem dos stakeholders preconiza que a empresa deve contemplar as várias partes interessadas envolvidas no negócio (por exemplo, trabalhadores, clientes, fornecedores, organizações comunitárias locais, além dos acionistas e proprietários), com benefícios que essas partes interessadas considerem importantes, pois a falta deste atendimento pode fazer com que esses grupos deixem de apoiar a empresa. Clarkson (1995) argumenta que as empresas se fortalecem quando demonstram suas responsabilidades para com a sociedade ligadas aos stakeholders, e por meio dessa ligação podem operacionalizar suas estratégias de RSC.

Frynas e Yamahaki (2016) afirmam que uma parte importante dos estudos sobre RSC baseados na abordagem das partes interessadas mostra uma relação com o desempenho organizacional ou desempenho financeiro, tanto no aspecto conceitual quanto no aspecto empírico; os resultados apontam para uma maioria com relação positiva e uma minoria com relação mista, inconclusiva ou mesmo negativa entre Responsabilidade Social Corporativa e desempenho organizacional. Apesar da abordagem dos stakeholders não ter sido criada para alicerçar a conceituação da RSC, conforme ressaltado por Dias, Pardini e Pompeu (2007), deve-se reconhecer que ela acabou sendo de grande aplicação nesta área. 
A abordagem institucional não tem visibilidade como perspectiva organizacional geradora de mudanças, mas fornece uma explicação da estabilidade de sistemas organizacionais em determinada população ou organizações (GREENWOOD; HININGS, 1996). Desse modo, ela sugere que as empresas precisam se conformar às normas sociais de um determinado ambiente de negócios, porque não podem sobreviver sem um nível de aprovação social (MEYER; ROWAN, 1977; DIMAGGIO; POWELL, 1983).

Frynas e Yamahaki (2016) observam que a abordagem institucional abrange três diferentes tradições e focos intelectuais, que podem ser divididos em abordagem econômica, sociológica e comparativa. A primeira aborda o papel regulador das instituições, que sustentam a atividade econômica; a sociológica aborda o papel de legitimidade das instituições; e a comparativa aborda as diferenças entre os arranjos institucionais que definem as economias capitalistas e moldam a organização econômica e a competitividade da empresa.

A abordagem institucional tem sido aplicada à RSC em muitos artigos (Quadro 1), que identificaram fatores institucionais que influenciam ou moldam o comportamento de responsabilidade social, a gestão das organizações, as práticas ambientais, e, ainda, a forma como as empresas publicam suas ações e resultados sociais e ambientais (FRYNAS; YAMAHAKI, 2016).

No âmbito da economia, se as empresas praticarem as mesmas "regras do jogo" os custos serão reduzidos, de modo que esse comportamento repetido gerará ganhos financeiros e, consequentemente, sob o ponto de vista econômico, passa a ser interessante para as organizações. No âmbito comportamental, considera que as mudanças na sociedade provocam mudanças nas organizações; portanto, uma tendência de as empresas copiarem umas às outras, principalmente as que forem percebidas como bem-sucedidas, passando a ser replicadoras do que conhecem e causando repetições de comportamentos. E no âmbito da abordagem comparativa, faz uma junção das duas anteriores (econômica e comportamental), pois normatiza as sistemáticas de divulgação de seus resultados (GALLÉN; PERAITA DELGADO, 2016).

Na revisão da literatura, identificou-se que os drivers constantes das duas perspectivas teóricas mais utilizadas (partes interessadas e institucional) são os drivers externos à organização, que direcionam o foco para a relação entre a empresa e a sociedade (FRYNAS; YAMAHAKI, 2016). Existem diferenças substanciais entre teorias de drivers externos e drivers internos. As teorias de drivers externos na pesquisa de RSC tendem a se concentrar nas relações entre a empresa e a sociedade, em que a RSC é o resultado de relações sociais e normas sociais. Os autores ressaltam ainda que uma combinação de duas ou mais teorias pode explicar melhor a RSC; principalmente, uma combinação de teorias relacionadas aos condutores internos e externos pode ajudar a esclarecer diferentes conjuntos de relações, incluindo a relação entre o contexto social e recursos organizacionais internos.

Conforme já exposto neste estudo, é difícil encontrar uma definição sobre RSC; Frynas e Yamahaki (2016) acreditam que a ampla cobertura de diferentes âmbitos e a falta de uma medida padrão são fatores que dificultam uma definição comum de RSC. O estudo de Dahlsrud (2008) apresentou 37 diferentes definições para RSC e incluíram a contagem da frequência de citações identificadas na plataforma Google, para todas as definições pesquisadas. 
Quadro 2. Definições de RSC DAHLSRUD (2008)

\begin{tabular}{|c|c|c|}
\hline Fonte & Definição & $\begin{array}{c}\text { Freq. } \\
\text { contagem } \\
\text { DAHLSRUD } \\
\end{array}$ \\
\hline Jones, 1980 & $\begin{array}{l}\text { A RSE é definida como a noção de que as empresas têm uma obrigação para com os grupos } \\
\text { constituintes da sociedade que não sejam os acionistas e além do prescrito por lei ou contrato sindical, } \\
\text { indicando que uma participação pode ir além da mera propriedade. }\end{array}$ & 15 \\
\hline Frederick et al, 1992 & $\begin{array}{l}\text { A responsabilidade social empresarial pode ser definida como um princípio que determina que as } \\
\text { empresas devem ser responsabilizadas pelos efeitos de qualquer ação em sua comunidade e meio } \\
\text { ambiente. }\end{array}$ & 1 \\
\hline Reder, 1994 & $\begin{array}{l}\text { Responsabilidade social corporativa refere-se à empresa na condução de suas operações internas, } \\
\text { incluindo a maneira como trata sua força de trabalho e seu impacto no mundo ao seu redor. }\end{array}$ & 1 \\
\hline Hopkins, 1998 & $\begin{array}{l}\text { A responsabilidade social corporativa está preocupada em tratar as partes interessadas da empresa de } \\
\text { forma ética ou socialmente responsável. As partes interessadas existem tanto dentro como fora da } \\
\text { empresa. Consequentemente, o comportamento socialmente responsável aumentará o } \\
\text { desenvolvimento humano das partes interessadas tanto dentro como fora da corporação, a RSC é um } \\
\text { termo que descreve a obrigação de uma empresa ser responsável perante todos os seus stakeholders } \\
\text { em todas as suas operações. }\end{array}$ & 21 \\
\hline $\begin{array}{l}\text { Conselho Empresarial } \\
\text { Mundial para o } \\
\text { Desenvolvimento } \\
\text { Sustentável, } 1999 \\
\end{array}$ & $\begin{array}{l}\text { O compromisso das empresas para contribuir para o desenvolvimento econômico sustentável, } \\
\text { trabalhando com funcionários, suas familias, a comunidade local e a sociedade em grande escala para } \\
\text { melhorar a sua qualidade de vida. }\end{array}$ & 180 \\
\hline Khoury et al., 1999 & $\begin{array}{l}\text { A responsabilidade social corporativa é a relação geral da corporação com todas as partes } \\
\text { interessadas. Estes incluem clientes, funcionários, comunidades, proprietários / investidores, governo, } \\
\text { fornecedores e concorrentes. Elementos de responsabilidade social incluem investimentos em } \\
\text { divulgação comunitária, relações com funcionários, criação e manutenção de empregos, gestão } \\
\text { ambiental e desempenho financeiro. }\end{array}$ & 48 \\
\hline $\begin{array}{l}\text { Kilcullen and Kooistra, } \\
1999\end{array}$ & $\begin{array}{l}\text { A RSE é o grau de obrigação moral que pode ser atribuído às corporações além da simples } \\
\text { obediência às leis do estado. }\end{array}$ & 2 \\
\hline Woodward-Clyde, 1999 & $\begin{array}{l}\text { CSR foi definido como um contrato entre sociedade e comunidade empresarial e concede a uma } \\
\text { empresa uma licença para operar e, em contrapartida, o negócio atende a certas obrigações e se } \\
\text { comporta de uma maneira aceitável. }\end{array}$ & 2 \\
\hline $\begin{array}{l}\text { Conselho Empresarial } \\
\text { Mundial para o } \\
\text { Desenvolvimento } \\
\text { Sustentável, } 2000\end{array}$ & $\begin{array}{l}\text { A responsabilidade social corporativa é o compromisso contínuo dos negócios de se comportar de } \\
\text { forma ética e contribuir para o desenvolvimento econômico, melhorando a qualidade de vida da força } \\
\text { de trabalho e suas famílias, bem como a comunidade local e a sociedade em geral. }\end{array}$ & 156 \\
\hline $\begin{array}{l}\text { Negócios para } \\
\text { Responsabilidade Social, } \\
2000\end{array}$ & $\begin{array}{l}\text { Operando um negócio de uma forma que atenda ou exceda as expectativas éticas, legais, comerciais e } \\
\text { públicas que a sociedade tem de negócios. A responsabilidade social é um princípio orientador para } \\
\text { cada decisão tomada e em todas as áreas de uma empresa. }\end{array}$ & 117 \\
\hline $\begin{array}{c}\text { Business for Social } \\
\text { Responsability, } 2000\end{array}$ & $\begin{array}{l}\text { Tomada de decisão nos negócios vinculada a valores éticos, atendimento aos requisitos legais e } \\
\text { respeito às pessoas, comunidades e meio ambiente. }\end{array}$ & 131 \\
\hline Piacentini et al., 2000 & $\begin{array}{l}\text { A RSE é a pretensão voluntária das empresas para além das responsabilidades puramente económicas } \\
\text { e legais. }\end{array}$ & 2 \\
\hline $\begin{array}{l}\text { Comissão dos europeus } \\
\text { com stakeholders } 2001\end{array}$ & $\begin{array}{l}\text { Responsabilidade social das empresas é essencialmente um conceito pelo qual as empresas decidem } \\
\text { voluntariamente contribuir para uma sociedade melhor. }\end{array}$ & 134 \\
\hline Marsden, 2001 & $\begin{array}{l}\text { A responsabilidade social corporativa (CSR) é sobre o comportamento central das empresas e a } \\
\text { responsabilidade pelo impacto total nas sociedades em que operam. O CSR não é um complemento } \\
\text { opcional nem um ato de filantropia. Uma corporação socialmente responsável é aquela que administra } \\
\text { um negócio lucrativo que leva em conta todos os efeitos ambientais, sociais e econômicos que tem } \\
\text { sobre a sociedade. }\end{array}$ & 11 \\
\hline $\begin{array}{l}\text { McWilliams and Siegel, } \\
2001\end{array}$ & $\begin{array}{l}\text { Ações que parecem promover algum bem social, além dos interesses da empresa e daquilo que é } \\
\text { exigido por lei. }\end{array}$ & 10 \\
\hline Pinney, 2001 & $\begin{array}{l}\text { A responsabilidade corporativa corporativa (CSR) ou cidadania corporativa pode ser definida } \\
\text { simplesmente como um conjunto de práticas de gestão que asseguram que a empresa minimiza os } \\
\text { impactos negativos de suas operações na sociedade e maximiza seus impactos positivos. }\end{array}$ & 5 \\
\hline UK Government, 2001 & $\begin{array}{l}\text { A responsabilidade social corporativa reconhece que os interesses comerciais mais amplos do setor } \\
\text { privado exigem que ela gerencie seu impacto na sociedade e no meio ambiente no sentido mais amplo. } \\
\text { Isso exige estabelecer um diálogo apropriado ou uma parceria com as partes interessadas relevantes, } \\
\text { sejam funcionários, clientes, investidores, fornecedores ou comunidades. A RSE vai além das } \\
\text { obrigações legais, abrange o envolvimento voluntário liderado pelo setor privado, que reflete as } \\
\text { prioridades e características de cada negócio, bem como fatores setoriais e locais. }\end{array}$ & 2 \\
\hline Foran, 2001 & $\begin{array}{l}\text { A RSC pode ser definida como o conjunto de práticas e comportamentos que as empresas adotam } \\
\text { em relação à sua força de trabalho, em relação ao meio no qual suas operações são incorporadas à } \\
\text { autoridade e à sociedade civil. }\end{array}$ & 1 \\
\hline Van Marrewijk, 2001 & $\begin{array}{l}\text { Empresas com uma estratégia de RSE integram preocupações sociais e ambientais em suas operações } \\
\text { comerciais e em suas interações com seus stakeholders e demonstram abertamente seus } \\
\text { desempenhos. }\end{array}$ & 0 \\
\hline
\end{tabular}




\begin{tabular}{|c|c|c|}
\hline $\begin{array}{l}\text { Jackson and Hawker, } \\
2001\end{array}$ & $\begin{array}{l}\text { A responsabilidade social corporativa é como você trata seus funcionários e todas as partes } \\
\text { interessadas e o meio ambiente. }\end{array}$ & 0 \\
\hline $\begin{array}{l}\text { Commission of the } \\
\text { European Communities, } \\
2002\end{array}$ & $\begin{array}{l}\text { Responsabilidade social corporativa significa que as empresas têm responsabilidades e ações além de } \\
\text { suas obrigações legais e objetivos econômicos / comerciais. Essas responsabilidades mais amplas } \\
\text { cobrem uma série de áreas, mas são frequentemente resumidas como sociais e ambientais - onde } \\
\text { social significa que a sociedade é definida de maneira rotineira, e não simplesmente social, questões de } \\
\text { política. Isso pode ser resumido como a abordagem do triple bottom line: ou seja, social, econômico e } \\
\text { ambiental. }\end{array}$ & 5 \\
\hline Lea, 2002 & $\begin{array}{l}\text { A RSC pode ser definida como a integração e preocupações ambientais nas operações de negócios, } \\
\text { incluindo negociações com partes interessadas. }\end{array}$ & 1 \\
\hline Lea, 2002 & $\begin{array}{l}\text { A RSE é sobre empresas e outras organizações que vão além das obrigações legais de gerenciar o } \\
\text { impacto que elas causam no meio ambiente e na sociedade. Em particular, isso poderia incluir como as } \\
\text { organizações interagem com seus funcionários, fornecedores, clientes e as comunidades em que } \\
\text { operam, bem como a medida em que tentam proteger o meio ambiente. A RSC pode ser definida } \\
\text { como o conjunto de práticas. }\end{array}$ & 1 \\
\hline $\begin{array}{l}\text { Comissão das } \\
\text { comunidades européias, } \\
2003\end{array}$ & $\begin{array}{l}\text { A RSC é o conceito de que uma empresa é responsável pelo seu impacto em partes interessadas } \\
\text { relevantes. É o compromisso contínuo dos negócios de se comportar de forma justa e responsável e } \\
\text { contribuir para o desenvolvimento econômico, ao mesmo tempo em que melhora a qualidade de vida } \\
\text { da força de trabalho e suas famílias, bem como da comunidade local e da sociedade em geral. }\end{array}$ & 40 \\
\hline IBLF, 2003 & $\begin{array}{l}\text { Práticas de negócios abertas e transparentes baseadas em valores éticos e respeito pelos funcionários, } \\
\text { comunidades e meio ambiente, o que contribuirá para o sucesso empresarial sustentável. }\end{array}$ & 82 \\
\hline $\begin{array}{l}\text { Negócios para } \\
\text { Responsabilidade Social, } \\
2003 \mathrm{~b}\end{array}$ & $\begin{array}{l}\text { A responsabilidade social corporativa está conseguindo o sucesso comercial de formas que honram os } \\
\text { valores éticos e respeitam as pessoas, as comunidades e o ambiente natural. }\end{array}$ & 46 \\
\hline CSRwire, 2003 & $\begin{array}{l}\text { A RSC é definida como a integração de operações e valores de negócios, pelo qual os interesses de } \\
\text { todas as partes interessadas, incluindo investidores, clientes, funcionários e meio ambiente, estão } \\
\text { refletidos nas políticas e ações da empresa. }\end{array}$ & 31 \\
\hline $\begin{array}{l}\text { Ethics in Action Awards, } \\
2003\end{array}$ & $\begin{array}{l}\text { RSE é um termo que descreve a obrigação da empresa de prestar contas a todas as partes } \\
\text { interessadas em todas as suas atividades operacionais: as empresas socialmente responsáveis } \\
\text { consideram todo o escopo do impacto nas comunidades e no meio ambiente ao tomar decisões, } \\
\text { equilibrando as necessidades das partes interessadas com sua necessidade de produzir lucro. }\end{array}$ & 17 \\
\hline Hopkins, 2003 & $\begin{array}{l}\text { A RSE preocupa-se em tratar as partes interessadas da empresa de forma ética ou responsável. "Ético } \\
\text { ou responsável" significa tratar as partes interessadas de uma maneira considerada aceitável em } \\
\text { sociedades civilizadas. Social inclui responsabilidade econômica. As partes interessadas existem tanto } \\
\text { dentro da empresa quanto fora dela. O objetivo mais amplo da responsabilidade social é criar padrões } \\
\text { de vida cada vez mais altos, preservando ao mesmo tempo a lucratividade da corporação, para as } \\
\text { pessoas dentro e fora da corporação. }\end{array}$ & 14 \\
\hline $\begin{array}{l}\text { Ethical Performance, } \\
\qquad 2003\end{array}$ & $\begin{array}{l}\text { Na melhor das hipóteses, a RSE é definida como a responsabilidade de uma empresa pela totalidade } \\
\text { do impacto, com a necessidade de incorporar os valores da sociedade em suas operações centrais, } \\
\text { bem como no tratamento de seu ambiente social e fisico. A responsabilidade é aceita como } \\
\text { abrangendo um espectro desde o funcionamento de uma empresa lucrativa até a saúde e segurança do } \\
\text { pessoal e o impacto nas sociedades nas quais a empresa opera. }\end{array}$ & 6 \\
\hline $\begin{array}{l}\text { Global Corporate Social } \\
\text { Responsability Policies } \\
\text { Project, } 2003 \\
\end{array}$ & $\begin{array}{l}\text { A responsabilidade social corporativa global pode ser definida como práticas de negócios baseadas } \\
\text { em valores éticos e respeito às comunidades de trabalhadores e meio ambiente. }\end{array}$ & 6 \\
\hline IndianNGos.com, 2003 & $\begin{array}{l}\text { A responsabilidade social corporativa é um processo de negócios em que a instituição e os indivíduos } \\
\text { dentro são sensíveis e cuidadosos sobre o efeito direto e indireto de seu trabalho em comunidades } \\
\text { internas e externas, a natureza e o mundo exterior, práticas empresariais socialmente responsáveis. }\end{array}$ & 4 \\
\hline $\begin{array}{l}\text { Business for Social } \\
\text { Responsability, 2003a }\end{array}$ & $\begin{array}{l}\text { Práticas comerciais socialmente responsáveis fortalecem a responsabilidade corporativa, respeitando } \\
\text { os valores e interesses éticos de todas as partes interessadas. As práticas empresariais responsáveis } \\
\text { respeitam e preservam o ambiente natural. Ajudar a melhorar a qualidade e as oportunidades da vida, } \\
\text { capacitar as pessoas e investir nas comunidades onde uma empresa opera. }\end{array}$ & 3 \\
\hline Andersen, 2003 & $\begin{array}{l}\text { Definimos responsabilidade social corporativa para ampliar o interesse imediato de incluir os } \\
\text { concidadãos e a sociedade em que se vive e faz parte hoje, agindo com respeito pela futura geração e } \\
\text { natureza. }\end{array}$ & 1 \\
\hline Van Marrewijk, 2003 & $\begin{array}{l}\text { Sustentabilidade corporativa e RSC referem-se às atividades da empresa - voluntárias por definição - } \\
\text { demonstrando a inclusão social e ambiental, preocupações nas operações de negócios e nas } \\
\text { interações com as partes interessadas. }\end{array}$ & 0 \\
\hline Strategis, 2003 & $\begin{array}{l}\text { A RSC é geralmente vista como contribuição empresarial para o desenvolvimento sustentável, que foi } \\
\text { definido como um desenvolvimento que atende às necessidades do presente sem comprometer a } \\
\text { capacidade das gerações futuras de atender suas próprias necessidades, e é geralmente entendido } \\
\text { como focado em como alcançar a integração econômica, ambiental e social. }\end{array}$ & 0 \\
\hline $\begin{array}{l}\text { Comissão da comunidade } \\
\text { Europeia (2011) }\end{array}$ & $\begin{array}{l}\text { A CSR é definida como a noção de que as Corporações têm uma obrigação para grupos constituintes } \\
\text { na sociedade além dos acionistas e além da prescrita por lei ou contrato de sindicato, indicando que } \\
\text { uma participação pode ir além da mera propriedade. }\end{array}$ & 286 \\
\hline
\end{tabular}

Fonte: Traduzido de DAHLSRUD (2008) 
A contagem de frequências identificou seis estudos com apenas uma citação e quatro estudos com nenhuma citação. Partindo do pressuposto de que a relevância do conceito é função de sua utilização, foram excluídos da análise os conceitos cuja frequência foi zero ou um. Para que fosse possível verificar o uso relativo de cada conceito, conforme proposto por Dahlsrud (2008), adotou-se o mesmo critério empregado pelo autor; contagem da repetibilidade das mesmas descrições bibliográficas utilizadas pelo autor, verificando-se a frequência de ocorrência na plataforma de dados do Google, ampliando o estudo realizado por Dahlsrud (2008) até 2018. Para verificar a trajetória dos conceitos apresentados por Dahlsrud (2008) ao longo do tempo, agruparam-se os trabalhos por autores e por décadas, como recorte temporal, considerando os que sucederam nas décadas de 1980, 1990 e nos anos de 2000 a 2010, e 2011 a 2018, conforme mostra o Quadro 3.

Quadro 3. Trajetória dos conceitos de RSC apresentados por Dahlsrud (2008)

\begin{tabular}{|c|c|c|c|c|c|}
\hline \multirow[b]{2}{*}{ Fonte } & \multicolumn{4}{|c|}{ Contagem frequencia no Google } & \multirow[b]{2}{*}{ Mini Gráfico } \\
\hline & $\begin{array}{l}\text { Década } \\
\text { de } 80\end{array}$ & $\begin{array}{l}\text { Década } \\
\text { de } 90\end{array}$ & $\begin{array}{c}\text { Anos } 2000 \\
\text { a } 2010\end{array}$ & $\begin{array}{c}\text { Anos } 2011 \\
\text { a } 2018\end{array}$ & \\
\hline UK Government, 2001 & 0 & 0 & 20800 & 17700 & \\
\hline $\begin{array}{l}\text { Conselho Empresarial Mundial para o Desenvolvimento } \\
\text { Sustentável, } 1999\end{array}$ & 0 & 1260 & 18300 & 17300 & \\
\hline Negócios para Responsabilidade Social, 2000 & 0 & 0 & 17800 & 19000 & \\
\hline Business for Social Responsability, 2000 & 0 & 0 & 17800 & 19000 & \\
\hline Business for Social Responsability, 2003a & 0 & 0 & 19100 & 17200 & \\
\hline Ethics in Action Awards, 2003 & 0 & 0 & 18400 & 17400 & \\
\hline $\begin{array}{l}\text { Conselho Empresarial Mundial para o Desenvolvimento } \\
\text { Sustentável, } 2000\end{array}$ & 0 & 0 & 18100 & 17600 & \\
\hline Ethical Performance, 2003 & 0 & 0 & 18000 & 17400 & \\
\hline Negócios para Responsabilidade Social, 2003b & 0 & 0 & 16400 & 18700 & \\
\hline Comissão das comunidades européias, 2003 & 0 & 0 & 13700 & 17200 & \\
\hline Marsden, 2001 & 0 & 0 & 40 & 16100 & \\
\hline $\begin{array}{l}\text { Comissão dos europeus com as suas partes interessadas de } \\
\text { forma voluntária } 2001\end{array}$ & 0 & 0 & 5420 & 8590 & \\
\hline Comissão da comunidade Europeia (2001) & 0 & 0 & 5420 & 8590 & \\
\hline McWilliams and Siegel, 2001 & 0 & 0 & 5864 & 5210 & \\
\hline Jones, 1980 & 1173 & 667 & 3270 & 5420 & \\
\hline Hopkins, 1998 & 316 & 399 & 2490 & 245 & \\
\hline CSRwire, 2003 & 0 & 0 & 423 & 783 & \\
\hline IBLF, 2003 & 0 & 0 & 447 & 562 & \\
\hline Hopkins, 2003 & 0 & 0 & 177 & 385 & \\
\hline $\begin{array}{l}\text { Global Corporate Social Responsability Policies } \\
\text { Project, } 2003\end{array}$ & 0 & 0 & 186 & 176 & \\
\hline Pinney, 2001 & 0 & 0 & 31 & 245 & \\
\hline IndianNGos.com, 2003 & 0 & 0 & 83 & 58 & \\
\hline Kilcullen and Kooistra, 1999 & 0 & 0 & 11 & 52 & \\
\hline Khoury et al., 1999 & 0 & 0 & 7 & 51 & \\
\hline Woodward-Clyde, 1999 & 0 & 0 & 5 & 28 & \\
\hline Piacentini et al., 2000 & 0 & 0 & 4 & 26 & \\
\hline Commission of the European Communities, 2002 & 0 & 0 & 2 & 21 & \\
\hline
\end{tabular}

Fonte: Elaborado pela autora a partir de Dahlsrud (2008) 
Para o refinamento da análise da utilização dos conceitos de RSC apresentados por Dahlsrud (2008), foi feito um recorte por década dos resultados com maior frequência de ocorrência (ver Figura 2).

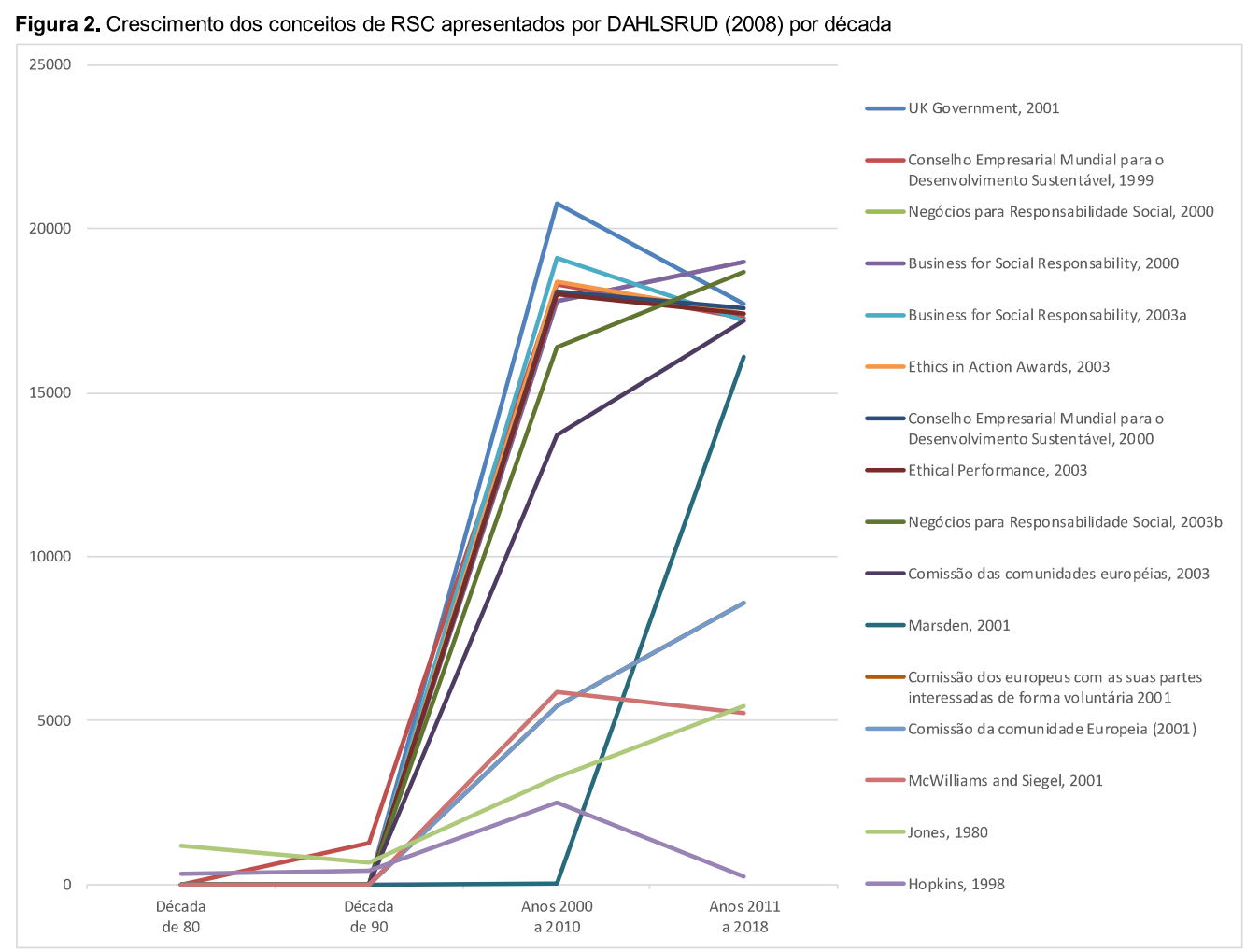

Fonte: Elaborado pela autora, baseado em DAHLSRUD (2008)

Dentre os conceitos mapeados por Dahlsrud (2008), é possível verificar que os das décadas de 1980 e 1990 são em número menor. O conceito de Jones (1980) foi o mais utilizado na década de 1980, decresceu na década de 1990 e voltou a crescer nos anos 2000. Apesar disso, seu uso não apresenta grande relevância em relação ao total de utilização dos conceitos mais empregados na última década, que foram: UK Government (2001), Conselho Empresarial Mundial para o Desenvolvimento Sustentável (1999), Negócios para Responsabilidade Social (2000) e Business for Social Responsibility (2000), entre outros.

O conceito mais utilizado na última década - UK Government (2001) - obteve apenas duas citações na contagem feita por Dahlsrud (2008). O segundo conceito mais utilizado na última década - Conselho Empresarial Mundial para o Desenvolvimento Sustentável (1999) foi o segundo mais citado na contagem do autor; o terceiro conceito mais citado na última década - Negócios para Responsabilidade Social (2000) - também foi o terceiro na contagem de Dahlsrud (2008). Vale ressaltar que o conceito mais citado no estudo de Dahlsrud (2008) é o décimo colocado entre os mais citados na última década.

\subsubsection{Dimensões éticas da RSC}

Estudos sobre ética indicam três tipos fundamentais de ética normativa: ética da virtude, teleológica e deontológica. A ética da virtude sugere que o caráter moral de uma entidade é a força motriz do comportamento ético (KOEHN, 1995, 1998; MOORE, 2005; MURPHY, 1999; WHETSTONE, 2001). A ética teleológica enfatiza os resultados das ações e orienta práticas focadas nos resultados da ação original. A ética teleológica prevê uma visão de consequência, e argumenta que o melhor determinante do que é moralmente correto é o valor não-moral da ação (CHAKRABARTY; BASS, 2015). A ética deontológica descreve ações éticas conduzidas por deveres ou regras (KOEHN, 1995; RAWWAS; SWAIDAN; OYMAN, 2005). 
A ética deontológica pode ser associada à abordagem dos stakeholders, pois a empresa coloca empenho para atender aos interesses dos stakeholders e persegue o intento de cumprir compromissos e deveres com as partes interessadas (FRYNAS; YAMAHAKI, 2016). Da mesma forma, a ética deontológica pode ser associada à abordagem institucional, pois o isomorfismo proposto por esta abordagem prevê repetições de ações e comportamentos, para condicionar uma aceitação do ambiente pela replicação de comportamentos, de modo que estes não sejam oriundos de princípios norteadores, mas do cumprimento de regras e deveres que replicam o "modus operandi" da organização e legitimam sua existência.

Para identificar as dimensões éticas dos conceitos de RSC identificados por Dahlsrud (2008), procedeu-se a uma análise do seu conteúdo com base na proposta de Bardin (1977), com vistas a analisar a orientação ética dos conceitos.

Foram respeitadas as etapas de recorte, enumeração e categorização preconizadas pela psicóloga parisiense. Com relação ao recorte, esta primeira etapa, caracterizada pela préanálise do material, percorreu as etapas descritas a seguir: a priori, realizou-se leitura flutuante dos conceitos para estabelecer contato e uma primeira percepção sobre aqueles a serem estudados. Para constituir o corpus, foram selecionados os 37 conceitos apresentados por Dahlsrud (2008). Utilizando a regra da representatividade proposta por Bardin (1977), optou-se por excluir da análise os conceitos cuja frequência foi zero ou um, por serem entendidos como conceitos com baixa representatividade; assim, 27 conceitos foram utilizados do universo inicial.

A segunda etapa representa a exploração do material, contendo a unidade de registro e a unidade de contexto, e nela os conceitos foram estruturados de modo a serem inventariados. Foi utilizado o seguinte critério: para que fosse possível compreender o núcleo central do conceito, buscou-se identificar o substantivo que melhor o traduzia, destacando-o do próprio texto dos conceitos. Cada um foi caracterizado pelo emprego da regra de enumeração presença/ausência, verificando-se a aparição dos mesmos termos considerados como unidade de registro dos conceitos apontados no estudo de Dahlsrud (2008).

$\mathrm{Na}$ terceira etapa (tratamento dos dados, inferência e interpretação) foi feita a categorização, que é, de acordo com Bardin (1977), uma operação de classificação de elementos constitutivos de um conjunto por diferenciação e, em seguida, por reagrupamento. A categorização, a posteriori, foi realizada mediante o agrupamento dos substantivos encontrados na análise dos conceitos, agrupados em dois conjuntos de categorias: dimensão deontológica e dimensão teleológica. A dimensão deontológica foi manifestada pelos seguintes substantivos: compromisso, gerenciamento do impacto, obrigação, princípio orientador para a decisão, decisão, valores éticos e respeito, comportamento central, decisão voluntária, decisão, preocupação e gerenciamento do impacto. A dimensão teleológica foi configurada a partir dos seguintes substantivos centrais: práticas, valores éticos e respeito, comportamento central, decisão voluntária, ações, integração e pretensão.

Para que os substantivos centrais de cada conceito pudessem ser classificados nas dimensões éticas e agrupados em categorias, recorreu-se ao dicionário etimológico de Cunha (2007), para apreender o significado de cada termo, conforme segue:

Compromisso: comprometer; acordo, ajuste, obrigação. Do latim comprõmissum;

Obrigação: obrigar, sujeitar, responsabilizar; dever; do latim obligatio - õnis;

A expressão "princípio orientador da decisão";

Princípio: principiar, começar, abrir. Do latim principium;

Decisão: decidir, resolver, determinar, sentenciar. Do latim decisio - ônis;

Orientação: oriundo de "Oriente": parte de onde nasce o sol. Pode-se entender de onde parte a decisão, para a expressão "orientador da decisão";

Preocupação: preocupar, aborrecer, inquietar. Do latim praeoccupãre;

A expressão "gerenciamento do impacto";

Gerenciamento: gerir, administrar, dirigir, regular. Do latim digerire;

Impacto: choque, colisão, efeito de uma ação forte, contundência. Do latim impactus;

De acordo com Cunha (2007), as definições etimológicas para estes substantivos centrais são:

Práticas: prática, uso, experiência, exercício. Do latim practica. 
A expressão "valores éticos e respeito"

Valor: audácia, vigor, mérito, importância, preço. Do latim valor-ôris.

Ética: ramo de conhecimento que estuda a conduta humana, estabelecendo conceitos entre o bem e o mal, numa determinada sociedade, numa determinada época. Do latim êthica.

Respeito: reverência, veneração, obediência. Do latim respectus.

A expressão "comportamento central"

Comportamento: comportar, permitir, admitir, suportar, proceder, portar-se, conter, abranger. Do francês comportement.

Centro: ponto para onde convergem as coisas, ponto interior equidistante de todos da circunferência ou da superfície de uma esfera. Central, do latim centrãlis.

A expressão "decisão voluntária"

Decisão: decidir, resolver, determinar, sentenciar. Do latim decisio - ônis. Voluntário: vontade, capacidade de escolha, de decisão, anseio, desejo. Do latim voluntas-atis.

Ações: ação, atuação, ato, feito, obra. Do latim ãctiõ-õnis.

Integração: integrar, completar, determinar a integral de uma função. Do latim integrãre.

Pretensão: direito suposto (ou real) e reivindicado. Do francês prétention.

Agrupando os autores que empregam conceitos que contemplam os mesmos substantivos, e somando o total de frequências de contagem entre os anos de 1980 a 2018, em paralelo à dimensão ética atribuída, foi encontrado o total das utilizações dos conceitos em suas dimensões éticas (Quadro 4).

Quadro 4. Dimensões éticas para a RSC

\begin{tabular}{|c|c|c|c|}
\hline Fonte & $\begin{array}{c}\text { Total de } \\
\text { contagem } \\
1980 \text { a } 2018 \\
\text { AUTORA } \\
\end{array}$ & $\begin{array}{c}\text { Análise dos Conceitos } \\
\text { Substantivo } \\
\text { AUTORA }\end{array}$ & $\begin{array}{c}\text { Ética } \\
\text { Teleológica } x \\
\text { Deontológica } \\
\text { AUTORA }\end{array}$ \\
\hline $\begin{array}{l}\text { Conselho Empresarial Mundial para o Desenvolvimento } \\
\text { Sustentável, } 1999 \\
\text { Conselho Empresarial Mundial para o Desenvolvimento } \\
\text { Sustentável, } 2000 \\
\text { Comissão das comunidades européias, } 2003 \\
\end{array}$ & 103460 & Compromisso & Deontológica \\
\hline $\begin{array}{l}\text { UK Government, } 2001 \\
\text { Ethical Performance, } 2003\end{array}$ & 73900 & Gerenciamento do impacto & Teleológica \\
\hline \begin{tabular}{|l} 
Jones, 1980 \\
Hopkins, 1998 \\
Kilcullen and Kooistra, 1999 \\
Woodward-Clyde, 1999 \\
Ethics in Action Awards, 2003 \\
Comissão da comunidade Europeia, 2001 \\
\end{tabular} & 63886 & Obrigação & Deontológica \\
\hline \begin{tabular}{|l|} 
Pinney, 2001 \\
IBLF, 2003 \\
Global Corporate Social Responsability Policies Project, \\
2003 \\
IndianNGos.com, 2003 \\
\end{tabular} & 38088 & Práticas & Teleológica \\
\hline Negócios para Responsabilidade Social, 2000 & 36800 & $\begin{array}{l}\text { Principio orientador para a } \\
\text { decisão }\end{array}$ & Deontológica \\
\hline Business for Social Responsability, 2000 & 36800 & Decisão & Deontológica \\
\hline Negócios para Responsabilidade Social, 2003b & 35100 & Valores éticos e respeito & Teleológica \\
\hline Marsden, 2001 & 16140 & Comportamento central & Teleológica \\
\hline Comissão dos europeus com stakeholders 2001 & 14010 & Decisão voluntária & Teleológica \\
\hline $\begin{array}{l}\text { McWilliams and Siegel, } 2001 \\
\text { Commission of the European Communities, } 2002\end{array}$ & 11097 & Ações & Teleológica \\
\hline CSRwire, 2003 & 1206 & Integração & Teleológica \\
\hline Hopkins, 2003 & 562 & Preocupação & Deontológica \\
\hline Khoury et al., 1999 & 58 & Relação & Não identificado \\
\hline Piacentini et al., 2000 & 30 & Pretensão & Teleológica \\
\hline
\end{tabular}

Fonte: Elaborado pelas autoras a partir dos conceitos apresentados por DAHLSRUD (2008)

Os resultados mostram que $56 \%$ dos conceitos analisados são orientados para a ética deontológica e $44 \%$ para a ética teleológica (Figura 3). Portanto, a maioria dos conceitos integra a ideia de que a RSC tem mais relação com deveres para com funcionários, clientes, comunidade e sociedade do que com consequências, em acordo com o estudo de Somerville e Wood (2012). 
Figura 3. Categorização dimensão ética para a RSC

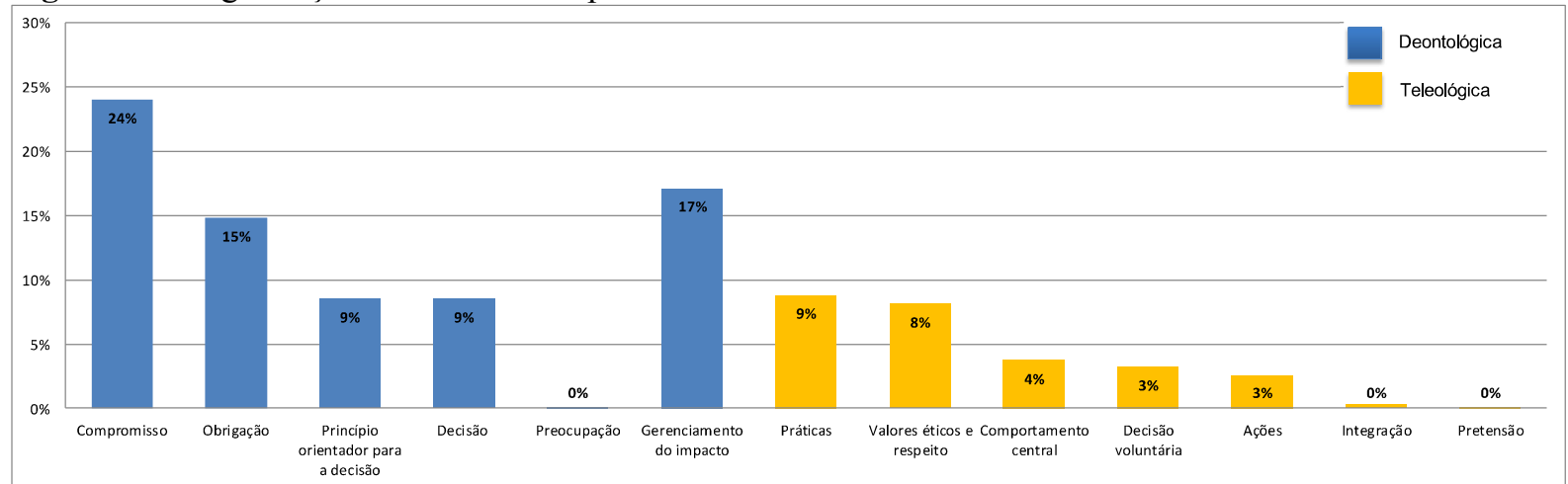

Fonte: Elaborado pelas autoras, baseado em DAHLSRUD (2008)

Verifica-se, portanto, que a frequência de utilização dos conceitos aponta maior proporcionalidade à dimensão ética deontológica. Fazendo essa análise ao longo do tempo, para verificar uma possível tendência dessa relação (Figura 4).

Figura 4. Análise de tendência das dimensões éticas no tempo

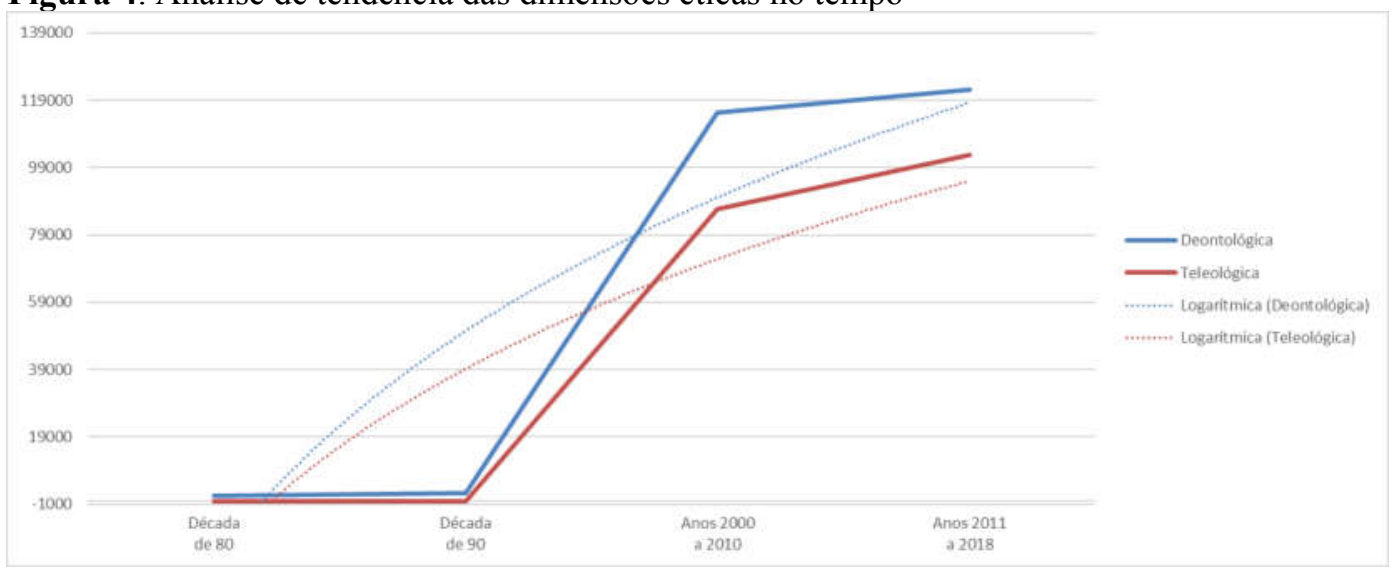

Elaborado pelas autoras a partir dos conceitos apresentados por DAHLSRUD (2008)

Observa-se que, até a década de 1990, ambas as dimensões éticas apresentaram níveis de ocorrências similares, e que entre as décadas de 1990 e 2000 a dimensão deontológica obteve intensidade de crescimento superior à teleológica. Comparando as tendências e as dimensões éticas ao longo do tempo (Figura 4), em relação aos marcos históricos que envolvem a RSC apresentados neste estudo (Figura 1), verifica-se que a partir do ano de 2010, os níveis de intensidade relativa permaneceram como na década anterior, porém a diferença entre as duas éticas foi menor, com aumento na utilização de conceitos relacionados à ética teleológica. 


\section{Conclusão}

A produção cientifica sobre responsabilidade social foi revisada a fim de retratar o contexto de publicações sobre o tema. Para contextualização, o estudo foi estruturado de modo a percorrer os marcos históricos da RSC, verificando quais as abordagens teóricas utilizadas nos estudos sobre o tema, cujas abordagens mais utilizadas apontam para a importância de considerar e fortalecer o interesse das partes interessadas ao demonstram suas responsabilidades para com a sociedade ligadas aos stakeholders; a normatização dos fatores institucionais que influenciam ou moldam o comportamento de responsabilidade social, a gestão das organizações, as práticas ambientais, e, ainda, a forma como as empresas publicam suas ações e resultados sociais e ambientais. (FRYNAS; YAMAHAKI, 2016).

Os estudos sobre responsabilidade social corporativa evidenciam inconsistência conceitual e um grande aumento do interesse pelo tema a partir dos anos 2000. As repetições da variedade de conceitos criaram uma espécie de universalidade no discurso sobre o tema, mas não tem sido capaz de atender às demandas da sociedade para as discussões sobre o assunto, passando a ser usada como estratégia de mercado e episódio institucional das organizações.

A maioria dos conceitos sobre RSC estão focalizados no cumprimento de obrigações legais, este dado pode significar uma tentativa das Organizações na institucionalização das atividades de Responsabilidade Social Corporativa para normatizarem seus discursos em relação a devolução que fazem a sociedade em troca da obtenção de seus lucros. Infere-se que os escândalos éticos que abalam a sociedade atualmente venham a legitimar uma mudança de tendência, pautada na redução da diferença entre os conceitos relacionados à ética teleológica, direcionando a necessidade da ampliação do conceito de modo que este seja capaz de associar a RSC a uma maior relação com os resultados das ações voltadas aos stakeholders, e não somente ao cumprimento de deveres associados a eles. 


\section{REFERÊNCIAS}

BARDIN, L. L’Analyse de Contenu. Paris: Presses Universitaires de France, 1977.

BOULOUTA, I.; PITELIS, C. N. Who needs CSR? The impact of corporate social responsibility on national competitiveness. Journal of Business Ethics, v. 119, n. 3, p. 349-364, 2014

BOWEN, H. R. Social responsibility of the businessman. New York: Harper \& Row, 1953.

CARROLL, A. B. A three-dimensional conceptual model of corporate performance. Academy of Management Review, v. 4, n. 4, p. 497-505, 1979.

CARROLL, A. B. Corporate social responsibility. Organizational dynamics, v. 44, n. 2, p. 8796, 2015.

CHAKRABARTY, S.; BASS, A. E. Comparing virtue, consequentialist, and deontological ethics-based corporate social responsibility: Mitigating microfinance risk in institutional voids. Journal of Business Ethics, v. 126, n. 3, p. 487-512, 2015.

CHAN, D. K. The concept of human dignity in the ethics of genetic research. Bioethics, v. 29, n. 4, p. 274-282, 2015.

CLARKSON, M. B. E. A stakeholder framework for analyzing and evaluating corporate social performance. Academy of Management Review, v. 20, n. 1, p. 92-117, 1995.

CUNHA, A. G. Dicionário etimológico da língua portuguesa. Rio de Janeiro: Lexicon Editora digital, 2007.

DAHLSRUD, A. How corporate social responsibility is defined: an analysis of 37 definitions. Corporate Social Responsibility and Environmental Management, v. 15, n. 1, p. 1-13, 2008.

DUQUE OROZCO, Y. V.; CARDONA ACEVEDO, M.; RENDÓN ACEVEDO, J. A. Responsabilidad social empresarial: Teorías, índices, estándares y certificaciones. Cuadernos de Administración (Universidad del Valle), v. 29, n. 50, p. 178-206, 2013.

DIAS, A. N. F.; PARDINI, D. J.; POMPEU, A. A teoria institucional e o espírito do capitalismo como pilares teóricos para estudar a evolução das ações sociais de uma empresa do setor siderúrgico. Revista Alcance, v. 14, n. 3, p. 447-468, 2007.

DIMAGGIO, P.; POWELL, W. W. The iron cage revisited: Collective rationality and institutional isomorphism in organizational fields. American Sociological Review, v. 48, n. 2, p. 147-160, 1983.

DONALDSON, T.; PRESTON, L. E. The stakeholder theory of the corporation: Concepts, evidence, and implications. Academy of Management Review, v. 20, n. 1, p. 65-91, 1995.

FREEMAN, R. E. Strategic management: A stakeholder approach. Boston: Pitman, 1984.

FREEMAN, R. E. Divergent stakeholder theory. The Academy of Management Review, v. 24, n. 2, p. 233-236, 1999.

FREEMAN, R. E.; REED, D. L. Stockholders and stakeholders: A new perspective on corporate governance. California Management Review, v. 25, n. 3, p. 88-106, 1983.

FRIEDMAN, M. Capitalism and freedom. Chicago: University of Chicago Press, 2009.

FRYNAS, J. G.; YAMAHAKI, C. Corporate social responsibility: Review and roadmap of theoretical perspectives. Business Ethics: A European Review, v. 25, n. 3, p. 258-285, 2016.

FORD, J. B. What do we know about corporate social responsibility messaging? Journal of Advertising Research, v. 57, n. 4, p. 355-356, 2017.

GALLÉN, M. L.; PERAITA DELGADO, C. Información de responsabilidad social corporativa y teoría institucional. Intangible Capital, v. 12, n. 4, p. 942-977, 2016. 
GREENWOOD, R.; HININGS, C. R. Understanding radical organizational change: Bringing together the old and the new institutionalism. Academy of Management Review, v. 21, n. 4, p. 1022-1054, 1996.

HILL, C. W. L; JONES, T. M. Stakeholder-agency theory. Journal of Management Studies, v. 29, n. 2, p. 131-154, 1992.

JAWAHAR, I. M.; MCLAUGHLIN, G. L. Toward a descriptive stakeholder theory: An organizational life cycle approach. Academy of Management Review, v. 26, n. 3, p. 397-414, 2001.

MCWILLIAMS, A.; SIEGEL, D. S.; WRIGHT, P. M. Corporate social responsibility: Strategic implications. Journal of Management Studies, v. 43, n. 1, p. 1-18, 2006.

OKOYE, A. Theorizing corporate social responsibility as an essentially contested concept: is a definition necessary? Journal of Business Ethics, v. 89, n. 4, p. 613-627, 2009.

PASSADOR, C.; FERRAZ, M. G. L.; CANOPF, L. A responsabilidade social no ENANPAD. Revista Alcance, v. 14, n. 3, p.469-492, 2007.

ROWLEY, T. J. Moving beyond dyadic ties: A network theory of stakeholder influences. Academy of Management Review, v. 22, n. 4, p. 887-910, 1997.

SAEIDI, S. P. et al. How does corporate social responsibility contribute to firm financial performance? The mediating role of competitive advantage, reputation, and customer satisfaction. Journal of Business Research, v. 68, n. 2, p. 341-350, 2015.

SOMERVILLE, I.; WOOD, E. Public relations and corporate social responsibility. In: THEAKER, A. (Ed.). The Public Relations Handbook. 4 ed. New York: Routledge, 2012. p. 175-194.

WARTICK, S. L.; COCHRAN, P. L. The evolution of the corporate social performance model. Academy of Management Review, v. 10, n. 4, p. 758-769, 1985.

WOOD, D. J. Corporate social performance revisited. Academy of Management Review, v. 16, n. 4, p. 691-718, 1991. 